\title{
A Content Analysis of Hotel Advertisements in China
}

\author{
Li Ying-Zhou and Han Xing
}

\begin{abstract}
The competition of the hotel industry in China has become increasingly intensive because of the massive influx of international hotel chains and overbuilding of native hotels. This paper examines a total of $\mathbf{2 0 7}$ hotel print advertisements of China with the method of content analysis. Most of the headlines of the advertisements are vague phrases and company names. Each advertisement contains an average of 4.38 information cues, and the most popular cues are customer care, and public area $\&$ facilities. Illustrations are common used in Chinese hotel advertisements. The interiors of hotel without people as well as the staff of the hotels and customers are frequently used as illustrations. The research results suggest that Chinese hotel marketers should make good use of more effective and attractive headlines such as the third party endorsement and statistics. As consumers are paying more and more attention on the corporate social responsibility of the business organization, hoteliers should consider the publicity of their corporate social responsibility activities when preparing their advertisement plan.
\end{abstract}

Index Terms-Hotel advertisement, Chinese hotel, content analysis, information content.

\section{INTRODUCTION}

Accompanied by the rapid development of tourism industry in China, the hotel sector in China has experienced a dramatic growth as well. Since the implementation of the star-rating system in China's hotel sector in 1988, the number of the hotels in China has grown from 135 in 1989[1] to more than 13,000 by the end of August 2013[2], and this number was predicated to continue increasing. The everlasting increase of hotels as well as consumers' demand of quality service would necessarily intensify the competition among hotel industry. Hospitality service has the characteristic of intangibility and the ephemeral nature which makes it difficult for consumers to form a proper pre-understanding of the hotel service. Advertising provides an excellent solution to this problem for hoteliers. Although Withiam (1986) has suggested that Chinese hoteliers have increasingly realized the importance of capturing the customers' interest and employing the overall marketing orientation[3], other researchers have revealed Chinese hotel marketers ' weakness in adopting marketing strategies [4]-[6]. The emerging of Internet has offered a valuable addition to the marketing tools, thus online advertising has become a popular marketing means. However, traditional print advertisement is superior to online advertising in terms of memorability and affordability [7]. This study attempts to investigate to what extent and how Chinese hotel marketers utilize the advertisements by examining the hotel magazine

Manuscript received September 12, 2013; revised November 14, 2013.

Li Ying Zhou and Han Xing are with the Lanzhou University, China (e-mail: hanx2007@1zu.edu.cn). advertisements in China.

\section{LITERATURE REVIEW}

\section{A. Content Analysis}

Content analysis has always been frequently employed by the researchers to examine the information content of advertisements [8]-[11]. However, the use of the content analysis method in hotel marketing research is much less. Cohen's (1989) study discovered the frequently appeared "authenticity" image in hotel and tourism publicity and advertisements [12]. Luk, Tam, and Wong (1995) investigated the popular employed advertising strategies by hoteliers and found that hotel marketers in Hong Kong seem to prefer adopting conventional advertising techniques to promote hotel service [13]. Rocha, Borges, and Furtado (2010) adopted content analysis method to study hotels' using symbols in advertisements with similarities regarding both direct and subliminal messages [14]. Regarding the study of the hotel advertisements in China, Siu and Fung (1998) studied the level of information content of China's hotel advertisements with the method of content analysis [15]. Other studies centered on the content analysis of the information publicity in the websites of hotels in China [16], [17]. However, no major study has been conducted to study China's hotel advertisements in recent years.

\section{B. Information Content of Advertisements}

Resnik and Stern (1977) proposed that the degree of informativeness of an advertisement could be evaluated by the use of information content. Informative advertising was regarded as "socially good" [18], whereas the persuasive advertising was viewed as "socially bad" [19]. Researchers have revealed the positive effect of employing pictorial materials, such as illustration, picture and headline of print advertisement [20]. Therefore, this study attempts to study the use of headlines and illustrations, as well as the level of information content of the hotel advertisements in China.

Most researchers employed the evaluative criteria developed by Resnik and Stern (1977) to measure the level of information content of advertising [18]. There are 14 criteria in total, namely price, quality, performance, component or content, availability, special offers, taste, nutrition, packaging, guarantees or warranties, safety, independent-sponsored research, company-sponsored research, and new ideas. Resnik and Stern (1977) proposed that an advertisement could be viewed as informative if it contains at least one information cues, and the more the information cues adopted, the more informative the advertisement is [18]. Though popular employed, the evaluative criteria were also questioned by some researchers regarding its applicability. Resnik and Stern's criteria were 
originally used to examine the information content of television advertising, and most of the samples were consumer products [18]. Abernethy and Butler (1992) argues that Resnik and Stern's approach may not necessary be suitable for the advertisement of services industry, for example the hotel advertisement, may have fewer information cues than that of fast moving convenience goods [21]. In Siu and Fung's (1998) study of hotel advertisement, 11 of Rensik and Stern's evaluative criteria were adopted whereas the other three of them were regarded inapplicable and expelled, namely taste, nutrition, and packaging [15].

\section{Headlines of Advertisements}

The critical importance of headlines in capturing readers' attention is widely suggested by researchers [22], [23], [15]. On average, the number of the headline of an advertisement read by people were five times more than that of body copy [22]. Lowe (1992) developed eight types of headline for hotel advertisement, namely command, testimonial, the third party endorsement, dialogue, comparison, reasons why, promise, and statistics [23]. This classification was later adopted by Siu and Fung (1998) to analyze the use of headlines in hotel advertisements [15].

\section{Illustrations of Advertisements}

Like headlines, researchers also attach great importance of illustrations. Alesandrini (1983) argued that pictures not only highlight the message topic and its key points to the readers, but also conduce to catch the readers' attention [24]. Empirical studies have indicated pictures' superiority in memorability compared with words [25], [26]. Therefor, illustration is a critical complement to the headline and body copy of an advertisement, and assists the consumers' information processing and decision making [15]. Though researchers advocated the positive influence of illustration and using pictorial materials in an advertisement, the most studies of illustrations of advertisements concentrate on the visual component such as size, color, and format of the ads [27]-[30]. Regarding the study of hotel advertisements, Siu and Fung (1998) classified seven common used illustrations, namely the staff of the hotel, the general manager or top management of the hotel, customers of the hotel, exteriors of the hotel, interior of the hotel without people, interiors of the hotel with people, and others [15].

\section{METHOdOLOGY}

\section{A. Research Method}

This study employs content analysis to research on China's hotel advertisements. Content analysis is regarded as one of the five research traditions in the study of information content of advertising [29]. Researchers who adopt this method can extract and compare both quantitative and qualitative information against some theory so as to help improve the quality of inference and reach certain conclusions [30].

There are three main parts in the coding sheet: headline, information content, and illustration. This study adopted Lowe's (1992) classification to investigate the headlines of the hotel advertisements, which are the third party endorsement, statistics, promise, command, comparison, reasons why, dialogue and testimonial [23]. However, three more types were added based on the preliminary analysis: vague phrase, company name, and news. Vague phrase headline indicates the advertisement headline using vague or abstract descriptions that makes readers neither understand the headline easily, nor have clues about the sponsor of the advertisements. News headline means the one with publicity of news about the company such as the newly opened hotels or the changes of the hotel policy. Regarding the information content, the authors developed a coding framework based on the investigation of a pilot sample of hotel advertisements. The preliminary analysis revealed nine frequently used information cues, namely general description, hotel service, special offer, public area $\&$ facilities, price, customer care, staff quality, third party endorsement, and corporate social responsibility. Hotel service is further divided into five information cues: front office, guest room, food \& beverage, health \& recreation, conference \& business. Special offer is further divided into three information cues: vocation spending, whole family programme, and wedding celebration. Hence, a total of 15 information cues were developed for the study. Siu and Fung's (1998) classification was adapted to analysis the illustrations of the ads (both photographs and drawings), however, four more approaches are added according to the preliminary analysis: surroundings of the hotel, food \& beverage, flowers, and symbols of the hotels [15].

\section{B. Sample Design}

Tourists are the main marketing target of the hotel sector and the travel magazines provide a favored platform for the hotels to promote their services. Hence, two of the most popular travel magazines were selected for this study: Voyage (with a circulation of 315000 per month) and National Geographic Traveller (with a circulation of 4942000 per month). The magazine issues were selected from the period of January 2009 to June 2013.

\section{Selective Criteria}

First, an advertisement was chosen if the objective was a hotel located in China, belonged to a hotel management corporation with all the hotels under the corporation being located in China, or was an international hotel management corporation with the condition that the ads marketed the hotel networks in China. Second, taking the comparison purposes into consideration, the size of the hotel ads was controlled [31]. Advertisements with size equal to or larger than half page, full-page or two successive full-pages were selected for the study. Third, duplicated ads were excluded. As a result, 232 hotel ads were selected. A pilot coding of a sample of 25 ads by two coders was conducted to check the inter coder reliability, and a reliability of $92.94 \%$ was reached. The disagreements between the two coders among all items were discussed to reach more mutual agreements for the further study. The remaining 207 hotel ads were included into the final sample. Two coders each coded half of the final sample and $15 \%$ of the samples were coded independently by both coders to check the data reliability. The overall inter coder reliability was $93.76 \%$, which can be regarded as satisfactory. 
Two coders discussed all the disagreements and the final consentaneous results were used for the final analysis.

\section{FINDINGS}

\section{A. General Profile}

The present study employed a total of 207 hotel advertisements form two of the most popular travel magazines (143 form Voyage and 64 form National Geographic Traveller). There was an upward trend of the use of advertisement among hotel sector. There were 29 hotel ads in 2009, wheres this number increased to 73 in 2012. Regarding the locations, the sample covers hotels from 18 provinces in China and hotel management groups around the world. Among all the provinces, hotels in Hainan adopted print advertisement most (30.9\%), followed by Shanghai, Guangdong, and Beijing with around $10 \%$ of the sample respectively. Advertisements of hotels with 5 stars or of the equal level occupied the vast majority of the sample (97.1\%), whereas only five 4-star hotels and one 3-star hotel adopted print advertisements. The predomination of 5-star hotel advertisements may be resulted from the fact that the target readers of these two magazines are high-end consumers. Details are presented in Table I.

\begin{tabular}{|c|c|c|c|}
\hline & & $\mathrm{No}=207$ & $\%$ \\
\hline \multirow[t]{2}{*}{ Source } & Voyage & 143 & $69.1 \%$ \\
\hline & National Geographic Traveller & 64 & $30.9 \%$ \\
\hline \multirow[t]{5}{*}{ Year } & 2009 & 29 & $14.0 \%$ \\
\hline & 2010 & 45 & $21.7 \%$ \\
\hline & 2011 & 44 & $21.3 \%$ \\
\hline & 2012 & 73 & $36.3 \%$ \\
\hline & 2013(first half year) & 16 & $8.0 \%$ \\
\hline \multirow[t]{3}{*}{ Grade } & 5 star or equal level & 201 & $97.1 \%$ \\
\hline & 4 star or equal level & 5 & $2.4 \%$ \\
\hline & 3 star or equal level & 1 & $0.5 \%$ \\
\hline \multirow[t]{8}{*}{ Location } & Hainan & 64 & $30.9 \%$ \\
\hline & Shanghai & 21 & $10.1 \%$ \\
\hline & Guangdong & 21 & $10.1 \%$ \\
\hline & Macau & 20 & $9.7 \%$ \\
\hline & Beijing & 19 & $9.2 \%$ \\
\hline & Shandong & 12 & $5.8 \%$ \\
\hline & Others areas & 39 & $18.8 \%$ \\
\hline & Management groups & 11 & $5.3 \%$ \\
\hline
\end{tabular}

\section{B. Headlines}

Of the 207 hotel advertisements, 7 (3.38\%) ads did not have a headline. Among the 200 ads with a headline, nearly half of them $(48.00 \%)$ were vague ones, whereas company name $(32.50 \%)$ and news $(24.00 \%)$ were mostly employed among the hotel ads among the remaining advertisements. Other types of headlines, especially dialogue and reasons why were seldom used. Noticeably, there was no testimonial or third party endorsement headline found in the sample.
Details are presented in Table II.

TABLE II: DISTRIBUTION OF TYPES OF HEADLINES

\begin{tabular}{lll}
\hline \hline & $\mathrm{N}=200$ & $\%$ \\
\hline Vague phrase & 96 & $48.00 \%$ \\
Company name & 65 & $32.50 \%$ \\
News & 48 & $24.00 \%$ \\
Promise & 17 & $8.50 \%$ \\
Statistics & 5 & $2.50 \%$ \\
Comparison & 5 & $2.50 \%$ \\
Dialogue & 2 & $1.00 \%$ \\
Reasons why & 1 & $0.50 \%$ \\
Testimonial & 0 & $0 \%$ \\
Third party endorsement & 0 & $0 \%$ \\
\hline \hline
\end{tabular}

TABLE III: INFORMATION CONTENT OF HOTEL ADVERTISEMENTS

\begin{tabular}{lll}
\hline \hline & $\mathrm{N}=207$ & $\%$ \\
\hline Ads with no cue & 6 & $2.90 \%$ \\
Ads with $\geq 1$ cues & 201 & $97.10 \%$ \\
Ads with $\geq 2$ cues & 178 & $85.99 \%$ \\
Ads with $\geq 3$ cues & 157 & $75.85 \%$ \\
Ads with $\geq 4$ cues & 122 & $58.94 \%$ \\
Ads with $\geq 5$ cues & 94 & $45.41 \%$ \\
Ads with $\geq 6$ cues & 72 & $34.78 \%$ \\
Ads with cues $\geq 1$ 0cues & 6 & $2.90 \%$ \\
\hline \hline
\end{tabular}

\begin{tabular}{llll}
\multicolumn{4}{c}{ TABLE IV: DISTRIBUTION OF INFORMATION CUES } \\
\hline \hline Information Cues & & $\mathrm{N}=201$ & $\%$ \\
\hline Customer care & 107 & $54.59 \%$ \\
Public area \& facilities & & 101 & $50.25 \%$ \\
Price & & 98 & $48.76 \%$ \\
Hotel service & Food \& beverage & 92 & $45.77 \%$ \\
& Guest room & 80 & $39.80 \%$ \\
& Health \& recreation & 66 & $32.84 \%$ \\
& Conference \& & 29 & $14.43 \%$ \\
& business & & \\
Special offer & Front Office & 17 & $8.46 \%$ \\
& Vocation spending & 80 & $39.80 \%$ \\
& Programme for the & 33 & $16.42 \%$ \\
Shole family & & \\
Hotel style & Wedding celebration & 9 & $4.48 \%$ \\
Third-party endorsement & & 17 & $8.46 \%$ \\
Corporate social & & 17 & $8.46 \%$ \\
responsibility & & 11 & $5.47 \%$ \\
\hline \hline
\end{tabular}

\section{Information Content}

There were six of the 207 hotel advertisements containing no information cue $(2.90 \%)$, and the other 201 ads $(97.10 \%)$ had a total of 907 cues. There was even $2.90 \%$ of the sample containing 10 or more cues (see Table III). As a result, each ad contained an average of 4.38 cues. Resnik and Stern (1977) claimed that an advertisement could be regarded as informative if it had at least one cue according to their evaluation criteria [18]. Although this study adopted a new approach instead of Resnik and Stern's, the $97.10 \%$ of the sample could be considered as informative as well. As for the information cues, customer care $(54.59 \%)$, public area \& facilities $(50.25 \%)$, price $(48.76 \%)$, food \& beverage $(45.77 \%)$, guest room $(39.80 \%)$, and vocation spending $(39.80 \%)$ were used most. After these top six cues, the 
frequencies of the other nine cues were significantly lower. Details are presented in Table IV.

\section{Illustrations}

Only one of the 207 hotel advertisements did not employ illustrations. Most ads (184) ads employed photographs (88.89\%), 10 ads employed drawings $(4.83 \%)$, whereas the remaining 12 ads employed both photographs and drawings (5.80\%). Among the ads with illustrations, there were 685 photographs $(95.67 \%)$ and 31 drawings $(4.33 \%)$ used, with a total number of 716 illustrations. There for, there was an average of 3.5 illustrations employed per hotel advertisement. The most common used illustration was interiors of the hotel without people $(40.08 \%)$, followed by the staff of hotel $(20.95 \%)$, and customers $(15.22 \%)$. Details are presented in Table V.

\begin{tabular}{lll}
\multicolumn{3}{c}{ TABLE V: DISTRIBUTION OF ILLUSTRATIONS } \\
\hline \hline & $\mathrm{N}=716$ & $\%$ \\
\hline Interiors of the hotel without people & 287 & $40.08 \%$ \\
The staff of the hotel & 150 & $20.95 \%$ \\
Customers & 109 & $15.22 \%$ \\
Exteriors of the hotel & 84 & $11.73 \%$ \\
Interiors of the hotel with people & 79 & $11.03 \%$ \\
Surroundings of the hotel & 57 & $7.96 \%$ \\
Food \& Beverage & 15 & $2.09 \%$ \\
Flowers & 12 & $1.67 \%$ \\
Top management of the hotel & 4 & $0.68 \%$ \\
Symbols of the hotel & 4 & $0.56 \%$ \\
Others & 37 & $5.17 \%$ \\
\hline \hline
\end{tabular}

\section{DISCUSSION}

Headlines are considered as conducive to attract consumers' attention, and researchers advocated that Chinese hotel management should attach sufficient importance to headlines and try to adopt various types of headlines [15]. The present study reveals $96.62 \%$ of the sample using headlines, which is significantly higher compared with a previous study suggesting only around half of China's hotel ads adopting headlines [15]. It gives a suggestion that Chinese hotel management has recognized the function and the importance of headlines. However, nearly half of the headlines $(48 \%)$ used by the hotel ads are vague phrases. These abstract and subtle headlines (for example "power up", "your key to the sky", and "great story has no script") may attract readers' attention at the first sight, but there is a possibility of confusing customers at the same time. Print advertisements should avoid vague headline because it offers no clear-cut advantage over others [32]. Among the headlines with substantive meanings, company names $(32.50 \%)$ are mostly employed, which further reveals the defect of China's hotel advertisement. As Boduch (1999) argued that a company name headline cannot possibly help getting the best return on their advertising investment because consumers cannot see any benefit just form the company name [32]. Noticeably, whereas a previous study indicated third party endorsement as the most popular headline among China's hotel advertisements, there is no third party endorsement headline found in this previous study, nor is the testimonial headline [15]. The reason for this is uncertain, but a plausible explanation may be the prevailing distrust of the so-called third party or celebrities in modern China [33].

With respect to the information content, there are 201 out of 207 hotel advertisements $(97.01 \%)$ have one or more cues. A total of 907 cues are found, resulting an average of 4.38 cues in each ad. In addition, nearly $3 \%$ of the samples contain 10 or more cues. It suggests an improvement of China's hotel advertisements today regarding of the information content, as a previous study revealed $87.07 \%$ of China's hotel ads had one or more cues and only $3.45 \%$ of the sample had five or more cues. Specifically, customer care is the most frequent used cue $(54.59 \%)$. Acting as a service organization, hotels' favor of customer care in marketing is understandable because the delivery of hotel service centers on various interpersonal interactions between hotels and their consumers [34]. Public area \& facilities $(50.25 \%)$ is also a favored information cue because most of the hotels of the sample are high-end hotels and these hotels need to market their upscale public area and comprehensive facilities. Price $(48.76 \%)$ is the third most common cue. Noticeably, a vast majority of the price information provided on the hotel ads is not price discount, but the regular price of the hotels, which suggests Chinese hotel marketers, especially luxurious hotel marketers, do not adopt price reduction as promotion strategy, but showing the regular price in advertisements as basic information about their hotels. It is in consistent with the finding that price reduction is no longer a key factor influencing the customers' choice of hotels [35]. Other frequently employed information cues include food \& beverage (45.77\%) and guest room (39.80\%), which are both basic services of hotels. Hoteliers need to market the catering and room service provided because they are the basic service the customers would enjoy and customers would surely want to get useful information about them from the advertisements. Vocation spending is also a common used cue (39.80\%). This is not surprising because of the fact that a considerable number of advertisement sponsors were the resort hotels in Sanya. Corporate social responsibility is the last frequent used cue, although it has become a hot topic among hospitality industry as well as other industries [36].

Illustrations are popularly adopted among the hotel advertisements because they not only offer customers a live picture of the hotel [15], but also make the advertisement more attractive. Photographs are more favored illustration means than drawings. It is justified because photographs are trustworthier in showing the real situation about the hotels than the drawings. Interiors of the hotel without people are most showed in the hotel advertisements $(40.08 \%)$, the staff of hotel $(20.95 \%)$, and customers $(15.22 \%)$ come in the second and third places. Whereas a previous study revealed Chinese hoteliers' neglect of the use of illustrations with people to spark readers' imagination about the hotel service because hotel service frequently involve person to person contact [15], the present study may give a suggestion of Chinese hotel marketers' improvement in using illustrations with people. 


\section{CONCLUSION AND RECOMMENDATIONS}

Although a vast variety of hotel ads have headlines, nearly half of them are vague ones that are regarded as having little attraction to customers [32]. Chinese hotel marketers have realized the importance of the headline, but they do not fully utilize its function. Company name and news come as the next popular advertisement headlines in sequence, whereas the types of headlines classified by Lowe (1992) are much less found in this study (specifically, none of the headlines adopted testimonial or third party endorsement [23]. This study reveals high level information content of hotel advertisements in China. Customer care, public area \& facilities, price, and basic information about the hotel service such as food \& beverage and guest room cover the most advertisements contents, whereas there is a dramatic drop-off with the remaining ten cues. Illustrations are widely used in the hotel advertisements in China, and photographs are more favored than drawings. Not only interiors of the hotel without people are frequently appeared in the advertisements, but also the staff of hotel and customers are commonly shown in the ads. It indicates that Chinese hoteliers have attached considerable importance to the people interaction in hotel advertisements.

The booming and domestic demand in China's hotel industry coexists with fierce competition due to the massive influx of international hotel chains and overbuilding of native hotels [4], [37]. Marketing is an important issue for Chinese hoteliers because it assists capturing more guests. When developing an advertising plan, headlines, information content, and illustrations are critical factors that hotel marketers should not neglect [15]. Hotel advertisements should avoid using vague headlines, nor should they adopt company name as headlines because they have little attraction to customers. Other types of headlines are advised, for example, statistics, third party endorsement, and promise. In addition, hotel marketing should pay more attention to marketing the corporative social responsibility activities such as environmental implementations, because consumers are showing increasing interest in them [37], and the corporative social responsibility activities have positive influence in promoting the reputation and image of the hotels [38].

\section{ACKNOWLEDGMENT}

We gratefully thank Prof. Kara Chan (HKBU), Ms. Tuo Yan-zhen for their generous guidance for this research. We also thank Mr. Xu Xian-jun for collecting research materials and all his kind support.

\section{REFERENCES}

[1] China National Tourism Administration, China Tourism Yearbook 1990, China Tourism Press, 1991, pp. 257.

[2] Supervision Division of China National Tourism Administration. (August 2013). Bulletin of the star hotel statistics of the second quarter 2013. [Online]. http://www.cnta.gov.cn/html/2013-8/2013-8-27-9-9-34978.html

[3] G. Withiam, "Hotel advertising in the'80s: Surveying the field," Cornell Hotel and Restaurant Administration Quarterly, vol. 27, no. 1, pp. 32-55, Jan. 1986.
[4] H. Kong and C. Cheung, "Hotel development in China: A review of the English language literature," International Journal of Contemporary Hospitality Management, vol. 21, no. 3, pp. 341-355, March, 2009.

[5] R. Pine, H. Q. Zhang, and P. Qi, "The challenges and opportunities of franchising in China's hotel industry," International Journal of Contemporary Hospitality Management, vol. 12, no. 5, pp. 300-307. 2000.

[6] T. Q. Zou, "Strategies of Chinese hotel groups: development model and policy guidance," Seminar on Theories and Practices of Conglomerates in Chinese Hotels, Beijing, 1998, pp. 20-22.

[7] S. S. Sundar, S. Narayan, R. Obregon, and C. Uppal, "Does web advertising work? Memory for print vs. online media," Journalism and Mass Communication Quarterly, vol. 75, no. 4, pp. 822-835, 1998.

[8] F. S. A. Olayan and K. Karande, "A content analysis of magazine advertisements from the United States and the Arab world," Journal of Advertising, vo. 29, no. 3, pp. 69-82, 2000.

[9] R. Arambewela and M. J. Polonsky, "Exploring marketing to marketers: A content analysis of advertisements in marketing news over 15 years," Presented at ANZMAC 2009: Sustainable management and marketing conference, 2012.

[10] A. Biswas, J. E. Olsen, and V. Carlet, "A comparison of print advertisements from the United States and France," Journal of Advertising, vol. 21, no. 4, pp. 73-81, 1992.

[11] V. R. Henderson and B. Kelly, "Food advertising in the age of obesity: Content analysis of food advertising on general market and African American television," Journal of Nutrition Education and Behavior, vol. 37, no. 4, pp. 191-196, 2005.

[12] E. Cohen, "Primitive and remote: Hill tribe trekking in Thailand," Annals of Tourism Research, vol. 16, no. 1, pp. 30-61, 1989.

[13] S. T. Luk, J. L. Tam, and S. S. Wong, "Characteristics of magazine advertisements on hotel service: a content analysis," Journal of Travel and Tourism Marketing, vol. 4, no. 3, pp. 29-43, 1996.

[14] J. d. R. Neto, D. Borges, and E. Furtado, "Between words and wishes. Content analysis of hotel advertising," Estudios y Perspectivas en Turismo, vol. 19, no. 5, pp. 761-775.

[15] W.-S. Siu and M.-Y. Fung, "Hotel advertisements in China: A content analysis," Journal of Professional Services Marketing, vol. 17, no. 2, pp. 99-108, 1998.

[16] Y.-C. J. Hsieh, "Hotel companies' environmental policies and practices: A content analysis of their web pages," International Journal of Contemporary Hospitality Management, vol. 24, no. 1, pp. 97-121, 2012.

[17] X. Wu, "Performance evaluation of commercial web sites: An exploratory study of hotels in mainland China," Presented at Wireless Communications, Networking and Mobile Computing, 2008. WiCOM'08.

[18] A. Resnik and B. L. Stern, "An analysis of information content in television advertising," The Journal of Marketing, pp. 50-53, 1977.

[19] G. R. Laczniak, "Information content in print advertising," Journalism and Mass Communication Quarterly, vol. 56, no. 2, pp. 324-345, 1979.

[20] B. D. Cutler, R. G. Javalgi, and M. K. Erramilli, "The visual components of print advertising: A five-country cross-cultural analysis," European Journal of Marketing, vol. 26, no. 4, pp. 7-20, 1992.

[21] A. M. Abernethy and D. D. Butler, "Advertising information-services versus products," Journal of Retailing, vol. 68, no. 4, pp. 398-419, 1993.

[22] F. Buttle, Hotel and Food Service Marketing: A Managerial Approach, Cassell, 1993.

[23] E. Lowe, "The good advertisement guide for hotels, inns \& restaurants," Newspaper Advertisement Marketing Services, 1992.

[24] K. L. Alesandrini, "Strategies that influence memory for advertising communications," Information Processing Research in Advertising, pp. 65-82, 1983

[25] T. L. Childers and M. J. Houston, "Conditions for a picture-superiority effect on consumer memory," Journal of Consumer Research, pp. 643-654, 1984

[26] D. J. MacInnis and L. L. Price, "The role of imagery in information processing: Review and extensions," Journal of Consumer Research, pp. 473-491, 1987.

[27] R. Rettie and C. Brewer, "The verbal and visual components of package design," Journal of Product and Brand Management, vol. 9, no. 1, pp. 56-70, 2000.

[28] L. Teng, N. Ye, Y. Yu, and X. Wu, "Effects of culturally verbal and visual congruency/incongruency across cultures in a competitive advertising context," Journal of Business Research, 2013. 
[29] K. W. King, L. N. Reid, S. F. Tinkham, and J. Pokrywczynski, "The perceived informativeness of national and retail advertising," Current Issues and Research in Advertising, vol. 10, no. 1-2, pp. 173-197, 1987.

[30] S. T. Luk, J. L. Tam, and S. S. Wong, "Characteristics of magazine advertisements on hotel service: A content analysis," Journal of Travel and Tourism Marketing, vol. 4, no. 3, pp. 29-43, 1996.

[31] R. R. Harmon, N. Y. Razzouk, and B. L. Stern, "The information content of comparative magazine advertisements," Journal of Advertising, vol. 12, no.4, pp. 10-19, 1983.

[32] R. D. Boduch, Great Headlines-Instantly, 1999.

[33] M. Li, "On regulation of celebrity endorsement in China," Journal of Politics and Law, vol. 4, no. 1, pp. 153, 2011

[34] B. R. Lewis, "Customer care in service organisations," Management Decision, vol. 29, no. 1, 1999.

[35] E. S. Chan and S. C. Wong, "Hotel selection: When price is not the issue," Journal of Vacation Marketing, vol. 12, no. 2, pp. 142-159, 2006.

[36] K. H. Kang, S. Lee, and C. Huh, "Impacts of positive and negative corporate social responsibility activities on company performance in the hospitality industry," International Journal of Hospitality Management, vol. 29, no. 1, pp. 72-82, 2010.

[37] L. Yu, and G. Huimin, "Hotel reform in China a SWOT analysis," Cornell Hotel and Restaurant Administration Quarterly vol. 46, no. 2, pp. 153-169, 2005.

[38] X. Han and K. Chan, "Perception of green hotels among tourists in Hong Kong: An exploratory study," Services Marketing Quarterly, vol. 34, no. 4, pp. 339-352, 2013.

[39] J. L. Holcomb, R. S. Upchurch, and F. Okumus. "Corporate social responsibility: What are top hotel companies reporting?" International Journal of Contemporary Hospitality Management vol. 19, no. 6, pp. 461-475, 2007.

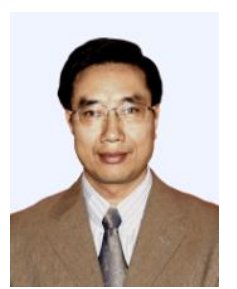

Li Ying-Zhou was born in the City of Tianshu in Gansu Province. In 1982, Li Ying-zhou graduated from Lanzhou University (Gansu, China) and incepted the bachelor's degree in History. Prof. Li joined in work form 1974. After graduating from Lanzhou University, he devoted himself to working for Lanzhou University as a instructor. He was the deputy director general of the Office of Academic Affairs in Lanzhou University from 1988 to 1990 . Then he was in charge of researching on Humanities \& Social Science for four years. In 1994, he held a post as the associate head of Information Management Department. After that, he became the head of the Department of Information Management in the School of Economy \& Management in 1998. In the meanwhile, he presided over all the work of researching institution of Information Management and applying the Master degree of information science. He is the professor and director in institution of International Tourism Management, with interest in tourism planning, cultural tourism, ethnic tourism, hospitality management, and tourism analysis and forecasting.

Prof. $\mathrm{Li}$ is also the director in Academic Council of Competitive Intelligence and the vice president of Scientific Committee of Scientific and Technological Information.

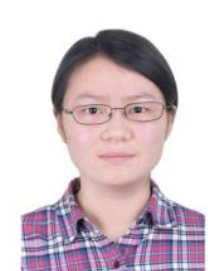

study.
Han Xing was born in the City of Wuwei in Gansu Province. In 2011, Han Xing graduated from Lanzhou University (Gansu, China) and incepted the bachelor's degree in Management. She pursued her study at Lanzhou University as a postgraduate student from 2011. She will get her master's degree in 2014. Miss Han majors in hotel management, and she concentrates on the study of environmental-friendly hotel, hospitality management and marketing, and consumer 